\title{
Relação \\ Fisioterapeuta-Paciente e a Integração Corpo-mente: um Estudo de Caso
}

Physiotherapist-

Patient Relationship and the Body-mind Integration: a Case Study

Relación Fisioterapeuta-

Paciente y la Integración

Cuerpo-mente: un Estudio de Caso

Clóris Regina Elias de Moraes Canto \& Lívia Mathias Simão

Universidade de São Paulo

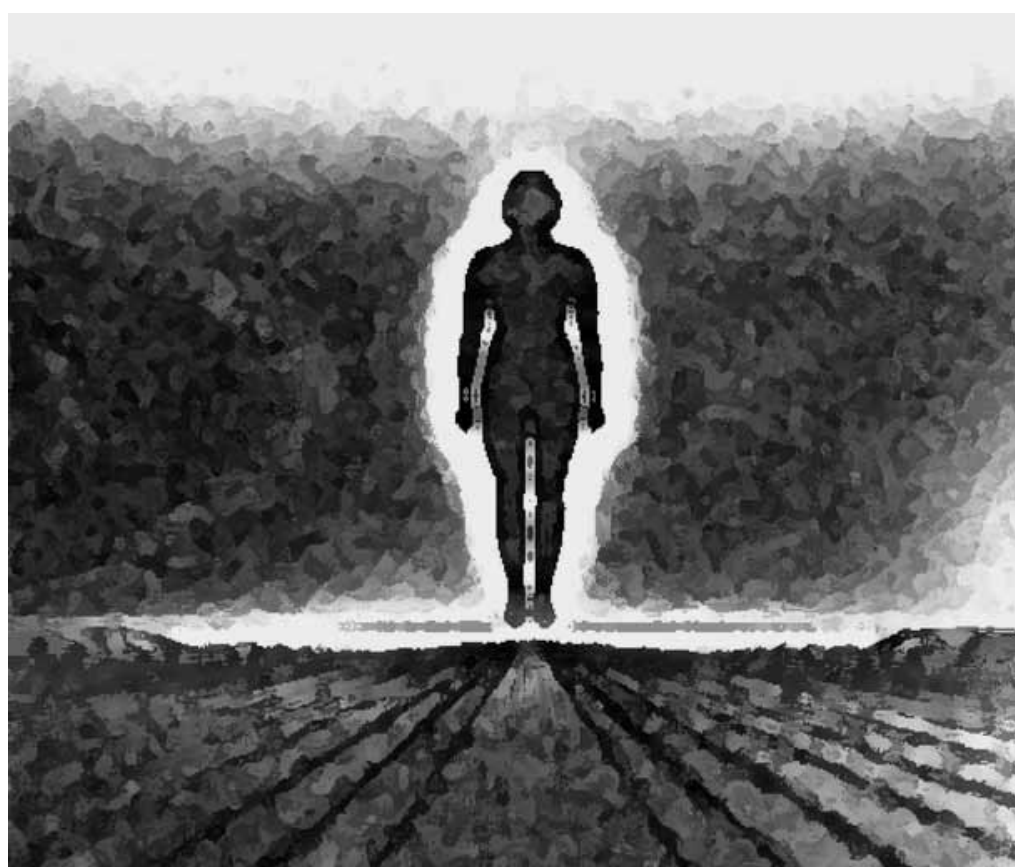


Resumo: A relação fisioterapeuta-paciente é usualmente caracterizada por momentos de tensão, originados da co-existência de seus diferentes mundos subjetivos, constituídos por concepções e valores diversos, incluindo-se aqueles atinentes à relação corpo-mente. Neste artigo, abordamos, através de relato de pesquisa com delineamento de estudo de caso, algumas das questões relacionadas às tensões intersubjetivas nesse contexto. Apresentaremos resultados da análise do diálogo entre uma fisioterapeuta e sua paciente que evidenciam suas perspectivas conflitantes quanto à relação corpo-mente, com desdobramentos específicos para o processo terapêutico assim como para aspectos gerais da vida cotidiana e profissional das participantes da relação. A análise do diálogo também evidenciou que a busca pela solução dos conflitos gerou, em alguns momentos, novas perspectivas na abordagem das participantes quanto aos temas dos diálogos e à própria relação fisioterapeuta- paciente. Pensamos que a reflexão e discussão desses aspectos nos campos da interdisciplinaridade entre Psicologia e fisioterapia podem gerar novas perspectivas de abordagem das relações envolvidas nesses contextos de atuação profissional.

Palavras-chave: Diálogo. Construção de conhecimento. Psicologia. Fisioterapia.

\begin{abstract}
The physiotherapist-patient relationship is usually characterized by moments of tension, yielded by the existence of their different subjective worlds. These worlds are constituted by the physiotherapist's and patient's different conceptions and values, included those concerning the mind-body relationship. In this paper we approach some questions related to the intersubjective tensions in this context, taking advantage of a case study. The analysis of the dialogue shows that the physiotherapist's and the patient's conflicting perspectives with respect to mind-body relation have implications for their professional and ordinary lives. It also shows that their quest for solving those conflicts brought, at some moments, new perspectives on the subject of the dialogues as well as on their ongoing relationship. We think that the interdisciplinary reflection and discussion of these aspects in the domains of psychology and physiotherapy can generate new perspectives for approaching the relationships involved in the respective professional contexts.
\end{abstract}

Keywords: Dialogue. Knowledge construction. Psychology. Physiotherapy.

Resumen: La relación fisioterapeuta-paciente es comúnmente caracterizada por momentos de tensión, originados de la co-existencia de sus diferentes mundos subjetivos, constituidos por concepciones y valores diversos, incluyéndose aquellos tocantes a la relación cuerpo-mente. En este artículo, abordamos, a través de relato de pesquisa con delineamento de estudio de caso, algunas de las cuestiones relacionadas a las tensiones ínter subjetivas en ese contexto. Presentaremos resultados del análisis del diálogo entre una fisioterapeuta y su paciente que evidencian sus perspectivas conflictivas en cuanto a la relación cuerpomente, con desdoblamientos específicos para el proceso terapéutico así como para aspectos generales de la vida cotidiana y profesional de las participantes de la relación. El análisis del diálogo también evidenció que la búsqueda por la solución de los conflictos engendró, en algunos momentos, nuevas perspectivas en el abordaje de las participantes en cuanto a los temas de los diálogos y a la propia relación fisioterapeutapaciente. Pensamos que la ponderación y discusión de estos aspectos en los campos de la interdisciplinaridad entre Psicología y fisioterapia pueden generar nuevas perspectivas de abordaje de las relaciones involucradas en esos contextos de actuación profesional.

Palabras clave: Diálogo. Construcción de conocimiento. Psicología. Fisioterapia.

Apesar de o avanço cultural e tecnológico ter possibilitado a cura para muitas patologias, notam-se, ainda, freqüentes discussões sobre as dificuldades para se dar conta das múltiplas demandas da relação profissional-paciente. No intuito de colaborar para essa discussão, destaca-se o objetivo desta pesquisa: abordar, através de um estudo de caso, algumas das questões relacionadas às relações corpomente nesse contexto dialógico, buscando contribuir para discussões interdisciplinares entre pesquisadores e profissionais de ambas as áreas envolvidas, no sentido de gerar novas perspectivas de abordagem dessas relações.

\section{Relação fisioterapeuta-paciente}

Desde muito tempo, estuda-se a relação entre corpo e alma. Inicialmente, o corpo foi considerado exclusivamente instrumento da alma, mas, com o dualismo cartesiano, corpo e alma passam a ser considerados duas substâncias diferentes e independentes. Essa forma de pensar influenciou e influencia 
É preciso considerar que a experiência de estar próximo ao sofrimento de outros (in)sensibiliza os profissionais que, por vezes, se recusam a conhecer as circunstâncias de vida do paciente, evitando 0 confronto com seus sentimentos, isso talvez pela crença de que sua formação profissional não abarque esses possíveis aspectos da vida humana

(Boesch, 1977). até hoje o pensamento médico-científico ocidental, que passa a conceber o corpo fragmentado em duas "partes": fisiológico e psicológico, destinando a diferentes especialistas o cuidado de cada uma de suas "partes". Nasce, aqui, a dificuldade da fisioterapia em considerar a dialogia corpomente, com implicação direta na relação fisioterapeuta-paciente.

Para o fisioterapeuta, tratar o paciente representa, muitas vezes, uma rotina: ele já está familiarizado com as doenças, seus sintomas, as reações dos pacientes e as restrições do tratamento, o que o leva a preocupar-se somente com a solução da queixa física do paciente. Expectativas e emoções diante da limitação física e do próprio tratamento não são, comumente, consideradas relevantes pelo profissional para o sucesso do tratamento. É preciso considerar que a experiência de estar próximo ao sofrimento de outros (in)sensibiliza os profissionais que, por vezes, se recusam a conhecer as circunstâncias de vida do paciente, evitando o confronto com seus sentimentos, isso talvez pela crença de que sua formação profissional não abarque esses possíveis aspectos da vida humana (Boesch, 1977), o que é legitimado, em parte, pela estrutura curricular dos cursos de formação profissional. Existe também a idéia - compartilhada por pacientes, familiares e profissionais - de que o afastamento emocional é facilitador da objetividade que acompanha a competência para a cura. Assim, conforme Boesch, o profissional desenvolve mecanismos de defesa que, dentre outras consequências, tenderão a substituir o indivíduo pelo caso clínico, convertendo a relação fisioterapeutapaciente em mais uma experiência técnica, reforçando o pensamento dicotômico corpomente e favorecendo o caráter rotineiro da atividade do profissional, ao evitar que ele se veja, a cada contexto socioemocional dos diversos pacientes, diante do desconhecido, do imprevisível, para o qual ele não se sente preparado.
Já para o paciente, as modificações decorrentes do processo de doença se iniciam antes de ele procurar o profissional. O paciente passa por um período - de duração variada - entre os primeiros sinais da doença e a rendição em aceitar o papel de doente, papel esse que tem seu significado variável de acordo com a cultura na qual o indivíduo se insere, podendo ser visto como fraqueza e equiparado ao fracasso, o que causa transtornos sociais, econômicos e emocionais e envolve o paciente e também sua família (Boesch, 1977). Portanto, nesse período, ele busca preservar sua autonomia funcional, tentando superar e minimizar a importância dos sintomas. Assim, para o paciente, a doença não é um fato corriqueiro, com manifestações conhecidas e soluções previsíveis, mas uma ameaça à sua integridade, não apenas física mas também psicossocial, o que lhe impõe um olhar intuitivamente mais integrado quanto à relação corpo-mente.

Nessa perspectiva, os papéis do fisioterapeuta e do paciente são construídos com base nas elaborações cognitivo-afetivas pessoais das sugestões culturais. Essa construção é um processo interativo que evidencia a assimetria inerente às relações sociais em geral. Da parte do profissional, inclui a elaboração de mensagens culturais com relação ao que é esperado da pessoa que ocupa aquele lugar: estabelecimento de regras, regulação de experiências e direção de comportamentos. São expectativas exigentes, mas prazerosas, porque propiciam algum sentimento de poder. Já o papel de paciente exige colocar-se no lugar de doente, o que é pouco prazeroso e bastante ameaçador.

A relação fisioterapeuta-paciente denota, então, a existência de perspectivas diferentes e irredutíveis com respeito à relação eumundo da fisioterapia: uma vivida pelo paciente - que envolve expectativas e medos baseados em aspectos sociais, culturais e emocionais de seu momento de vida - e 
outra pelo profissional da saúde - que tem suas preocupações voltadas para o caso clínico -, o que gera tensão, característica das relações interpessoais baseadas no diálogo, conforme Marková (1997). E é no bojo desse desequilíbrio cognitivo e afetivo, conforme a perspectiva de Simão (2000), que pode se dar a emergência de novos conhecimentos tanto sobre possibilidades e prognósticos para o quadro clínico como sobre maneiras de maximizar possibilidades interativas que os efetivem no tratamento. Assim, a vivência de uma contradição experimentada internamente poderá levar à tomada de consciência de que uma determinada idéia ou expectativa com que fisioterapeuta ou paciente operavam não lhes serve mais, o que acarreta sua transformação e, mais amplamente, seu desenvolvimento.

\section{A dialogia fisioterapeuta- paciente}

A reflexão advinda da idéia de que a vida de um indivíduo após algum evento - benéfico ou maléfico - nunca tem sua forma original restaurada nos remete ao potencial de mudança do ser humano: o "vir a ser", conforme Boesch (1991); essa idéia é freqüentemente vivenciada nas relações entre fisioterapeuta-paciente diante de um episódio de doença, em que o desejo de continuar igual ao que se era se potencializa, pois há a ameaça de "mudar para pior", que se torna assustadora para o paciente, para o fisioterapeuta e até mesmo para os grupos culturais aos quais pertencem. Dessa forma, é comum o paciente dizer: "Gostaria que minha vida voltasse a ser exatamente como era" e o terapeuta reforçar: "Procuraremos deixar sua vida como se nada tivesse acontecido".

Esse tipo de discurso traz a presença do futuro, como antecipação e imaginação, orientando a ação presente, isto é, o indivíduo está constantemente movendo-se do que é no minúsculo presente em direção ao ainda não determinado momento futuro (Abbey \& Valsiner, 2003). Esse movimento determina o novo presente, sendo a base para a próxima incerteza do futuro, que é então superada, infinita e irreversivelmente, o que ocorre por mediação semiótica, isto é, por um mecanismo funcional que transforma o futuro esperado (incerto, com possibilidades múltiplas) na possibilidade realizada e certamente acontecida (Simão, 2002), denotando um desenvolvimento baseado na incerteza. Quando em um tratamento fisioterapêutico, avançamos em exercícios com maior dificuldade, e é usual que a primeira atitude do paciente seja a rejeição ao exercício novo, segurando-se naquilo que já é capaz de fazer, em vez de enfrentar algo que não tem certeza se alcançará. Ao realizarmos esse avanço, oportunizamos ao indivíduo vivenciar essa ambivalência e encontrar mecanismos internos para a resolução desta, contribuindo para o desenvolvimento tanto no nível fisioterapêutico (melhora física) como no nível pessoal (melhora das capacidades de resolução de conflitos que envolvem incertezas e de projeção de um determinado futuro). Vale lembrar que a escolha do profissional e a permanência com este passam pelo sucesso ou insucesso da resolução desses conflitos, o que inclui empatia e confiança (Boesch, 1991). Tomando as proposições de Boesch (1991) e Simão (2002), a empatia se torna uma necessidade: fisioterapeuta e paciente precisam ser capazes de "ler" as intenções, discernir sentimentos, compreender gestos e captar os significados manifestos e latentes da linguagem de ambos, a fim de avaliar sua importância para os próprios objetivos, antecipando ações e reações, e de inferir sua avaliação sobre o outro. Ao entrar em contato com manifestações de algum sentimento experimentado pelo outro, fisioterapeuta e paciente aprendem as razões de esse sentimento ocorrer no outro e, em conseqüência, a conotação daquele sentimento para si próprio se alarga (Boesch, 1991). 


\section{A dialogia na corporeidade}

Para que uma pessoa se exprima enquanto corpo que realiza seus próprios desejos, é necessário que ela cresça não em sua individualidade absoluta, mas em suas relações com os outros e com o mundo (Gonçalves, 1994); aqui, particularmente, em sua relação com o fisioterapeuta. O contexto da fisioterapia, que busca a Reeducação Postural Global (RPG), toca a contínua (re) construção de um corpo, uma morada onde realizar a centralização e a unidade da pessoa (Denys-Struyf, 1995). Assim, nossos estados de tensão, nossas emoções, nossa maneira de ser, se exprimem através do sistema músculo-aponevrótico, influenciando nossa postura e nossos gestos, em uma relação dialógica. Portanto, a imagem do corpo passa pelas funções centrais da personalidade, enquanto representatividade do indivíduo para o mundo (Abraham, 1963), sendo, um fenômeno social (Schilder, 1980), revelando "instantâneos" na vida de uma pessoa (DenysStruyf, 1995).

Quando o paciente se olha no espelho prática freqüente da $\mathrm{RPG}$-, a imagem que faz de si é reveladora das representações que faz a seu próprio respeito, que dá ao indivíduo um conhecimento sobre si mesmo e sobre a consciência de sua própria perceptibilidade (La Taille, 2002), ou seja, não vê apenas o reflexo de seu Eu, vê sempre um personagem imaginário, localizado em um enredo de planos futuros e visto do ponto de vista do fisioterapeuta. Portanto, essas representações de si mesmo e as auto-avaliações do paciente diante do fisioterapeuta em relação à sua corporeidade e a seu comportamento têm vínculo estreito com os olhares judicativos deste e o de si mesmo, direcionando a interação; esse mesmo olhar judicativo recai sobre o fisioterapeuta como profissional. No entanto, a busca é sempre por representações positivas - uma das motivações básicas das condutas humanas, conforme La Taille.

\section{Estudo de caso}

\section{Participantes}

Participaram deste estudo um indivíduo (nomeado neste estudo paciente $[\mathbf{P}]$ ), sexo feminino, 49 anos, com queixa de dor na região da coluna lombar, encaminhado à fisioterapia para RPG por médico ortopedista do Hospital Israelita Albert Einstein (HIAE), São Paulo, com diagnóstico de lombalgia, e um profissional fisioterapeuta do HIAE (nomeado neste estudo fisioterapeuta $[\mathbf{P}]$ ), sexo feminino, 32 anos, com formação em RPG, atuando nessa especialidade e nessa instituição há cinco anos. Escolheu-se para esta pesquisa a análise do diálogo dessa paciente, pois, desde o primeiro momento de contato, a fisioterapeuta observou, da parte desta, comportamento mais reflexivo que o usual quanto ao tratamento e sua relação com a vida cotidiana, o que aumentaria a possibilidade de se obter informações relevantes, da perspectiva da paciente, sobre as questões que escolhemos nos debruçar neste estudo.

\section{Obtenção e registro das informações}

A coleta das informações realizou-se em uma sala para RPG do HIAE, que continha um espelho, além do mobiliário usual. As sessões foram individuais, com intervalo médio de sete dias entre elas.

As informações foram obtidas no processo interativo fisioterapeuta-paciente, através de entrevista dirigida pela fisioterapeuta. O acesso à participante se deu após parecer favorável da comissão de ética do HIAE e conseqüente autorização da instituição. Solicitou-se também a concordância da participante, através de assinatura do Termo de Consentimento Voluntário, em participar da pesquisa, esclarecendo-se que sua aceitação não era obrigatória para que se procedesse ao tratamento. Após essa assinatura, iniciouse a coleta dos dados pessoais (nome, idade 
e antecedentes clínicos) da participante e a mesma foi indagada pela fisioterapeuta quanto à sua sintomatologia. Com base em narrativa feita pela participante, e orientada por seu enquadre profissional, a fisioterapeuta passou aos procedimentos terapêuticos, incluindo a auto-avaliação da postura diante do espelho.

Os relatos da fisioterapeuta e da paciente durante o processo interacional nas 10 sessões do tratamento foram registrados em fitas cassete, com uso de um gravador comum. Posteriormente, foram transcritos pela pesquisadora, mantendo-se a forma de diálogo e seqüenciados com as denominações de $\mathbf{F}$ para a fisioterapeuta e $\mathbf{P}$ para a paciente.

Procedimento de análise

A análise das informações iniciou-se com a imersão da pesquisadora nos dados, deixando aflorar os sentidos possíveis quanto à apreensão das expectativas, motivações e interesses em relação ao tratamento fisioterapêutico, assim como em relação às concepções de integração corpo-mente. Evitou-se encapsular as informações em categorias, classificações ou tematizações de dados definidas a priori, utilizando-se uma orientação microgenética (Catan, 1989) na tarefa interpretativa dos sentidos das falas. Duas questões nortearam a interpretação do diálogo escolhido: "O que estaria levando $\mathbf{P}$ ou $\mathbf{F}$ a fazer/dizer isso?" e "Tendo uma delas (P ou $\mathbf{F})$ feito/dito isso, o que aconteceu com ambas?"

\section{Resultados e discussão}

A análise do diálogo entre $\mathbf{F}$ e $\mathbf{P}$ nas 10 sessões identificou um processo de construção de novos significados relativos ao processo fisioterapêutico bem de questões que tocam a corporeidade. Evidenciou-se o papel e o valor das trocas e negociações no espaço terapêutico, o que sugeriu que o trânsito de significações se constitui em canal ímpar na própria elaboração pessoal das participantes a respeito de si própria, da outra e das razões que as colocaram ali. Notou-se, em muitos momentos, a presença de ambigüidade nos sentidos das falas das participantes quanto a aspectos que ambas consideravam relevantes no tratamento, e mudanças de opiniões, principalmente quanto ao significado atribuído por uma às ações da outra e quanto às reflexões sobre suas vivências.

Os relatos de $\mathbf{P}$ apontaram mudanças de comportamento que não ficaram estritos apenas à resolução da queixa que a levou ao tratamento - a dor -, passando para um âmbito mais amplo da vida, incluindo sua auto-imagem e sua relação com novas propostas de vida. Com isso, queremos dizer que, se viver sem dor era o objetivo último do tratamento, há também que se considerar o fato de que $\mathbf{P}$ passou a perceber-se de forma diferente, em muitos sentidos "melhor", assim como os outros também passaram a percebêla dessa forma. Nessa medida, o objetivo da RPG pôde ser estendido a questões que tocam a qualidade de vida nas relações interpessoais e consigo mesmo.

Nesse processo dinâmico, $\mathbf{F}$ ocupou o lugar de organizadora das atividades terapêuticas, confirmando a $\mathbf{P}$ seu lugar de pessoa única, isto é, com problemas, razões e expectativas que, embora possam ser colocadas no fundo da generalidade dos conhecimentos da área científica da saúde, são ao mesmo tempo exclusivamente individuais em sua manifestação. $\mathbf{P}$, de sua parte, permitiu que $\mathbf{F}$ apreendesse aspectos importantes do tratamento, a partir da perspectiva interacional eu-outro, o que a fez refletir e imprimir mudanças em seu comportamento profissional e pessoal.

A seguir, sintetizamos momentos significativos do diálogo durante as sessões para ilustrar o discutido na seção Introdução - para íntegra da pesquisa ver Canto (2006). 
Primeira sessão

P afirmou ter uma "dor nas costas constante", constância essa que foi questionada por $\mathbf{F}$, gerando um momento de tensão e indicando a existência de duas perspectivas diferentes quanto ao caráter constante da dor referida por P. Talvez essa tensão tenha sido gerada pela falta de confiança de uma na outra: sem uma experiência prévia, $\mathbf{P}$ não sabia de fato se $\mathbf{F}$ iria ajudá-la; ela apenas supunha que a outra merecesse sua confiança, pois pressupunha seu preparo profissional, que Ihe é culturalmente sinalizado, por exemplo, pela pertença de $\mathbf{F}$ a uma instituição de saúde.

No intuito de resolver a tensão, F fez novo questionamento sobre as condições físicas de piora da dor; com isso, $\mathbf{P}$ experimentou a disposição e a preocupação da profissional, mas reafirmou que suas "costas doíam o tempo todo", apesar de demonstrar estar mais aberta à reflexão sobre o tema ao iniciar sua fala com "Uhmmm..." Nesse questionamento, F fez relação do quadro álgico com a questão espacial (posições corporais) e $\mathbf{P}$ respondeu em termos temporais: "doem o tempo todo", sugerindo dificuldade em transpor os limites temporais para os espaciais, que, no presente caso, pode ser considerado o próprio corpo. Nota-se, aqui, a freqüente inabilidade do profissional em indicar seu objetivo com clareza, na pergunta, assim como a do paciente em se expressar frente a ele e em delimitar seus sintomas, dando a sensação de falta de conhecimento de seu próprio corpo e de atenção para com suas próprias dificuldades, talvez evitando defrontar-se com elas.

Explorando mais a queixa de $\mathbf{P}, \mathbf{F}$ indagouIhe sobre as condições de alívio da dor, e $\mathbf{P}$ identificou uma posição corporal, solucionando a tensão e oportunizando nova etapa para o tratamento. Vale lembrar que a dificuldade de $\mathbf{P}$ em atender às solicitações de F pode ser entendida por esta como falta de reconhecimento de sua capacidade, fato que gerou sentimentos negativos em resposta às percepções desse comportamento. Mas, não fosse essa dificuldade, talvez a investigação de $\mathbf{F}$ fosse mais rápida e superficial e não resultasse em novas informações.

Na sequência, $\mathbf{F}$ buscou saber se $\mathbf{P}$ utilizava essa posição corporal para alívio da dor; ela respondeu que não, pois seu dia a dia era atribulado. Intuitivamente, F atribuiu essa condição a um excesso de atividade profissional, o que não foi validado por $\mathbf{P}$, ao afirmar ser o sono ruim o fator limitante. Notase o aparecimento da novidade, mudando a direção do raciocínio de $\mathbf{F}$ e oportunizando a aquisição de novos conhecimentos sobre o quadro clínico de $\mathbf{P}$.

$\mathbf{F}$, diante da novidade, indagou a $\mathbf{P}$ sobre o possível fator desencadeador do sono ruim, sugerindo uma inter-relação entre estados emocionais e físicos e também interesse por sua história de vida. Demonstrando mais confiança e empatia, $\mathbf{P}$ afirmou que foi após o término de seu casamento e o crescimento dos filhos que seus problemas de sono apareceram, denotando uma noção integrada de si, estabelecendo relação estreita entre aspectos físicos e emocionais na sua condição sintomática.

Mesmo tendo identificado a dificuldade de sono de $\mathbf{P}$, F explicitou ser necessário retomar o assunto que a trouxe ao tratamento (dor nas costas), não dando feedback às novas informações adquiridas, o que mostra dificuldade em lidar com temas que não têm relação direta com sua formação profissional (no caso, questões emocionais), embora o contato tenha acontecido. Ilustra, também, que o pensamento integrado corpo-mente fazia parte do raciocínio de $\mathbf{F}$, mas não gerou atitudes integradas em benefício direto a $\mathbf{P}$.

Em seguida, $\mathbf{F}$ solicitou a $\mathbf{P}$ uma autoavaliação postural. Nesta, $\mathbf{P}$ afirmou não ter uma ótima postura, por conta de eventos emocionais negativos em sua vida, indicando 
mais uma vez pensamento corpo-mente integrado. $\mathbf{F}$, apesar de se assentar em aspectos objetivos (alterações de postura visivelmente identificáveis), solicitou uma reflexão simbólica a $\mathbf{P}$ : "O que a senhora quer dizer quando afirma não ter uma ótima postura?", provavelmente por já ter aprendido que ela dava maior retorno verbal quando os aspectos simbólicos eram levados em conta, ou seja, passava a agir de acordo com o modo como experimentava as ações e reações de $\mathbf{P}$ na própria situação de interação. Além disso, $\mathbf{P}$ alegou que o tema postural era ligado à estética, e, portanto, não importava em seu momento de vida. No entanto, a auto-imagem negativa relatada anteriormente nos sugere que $\mathbf{P}$, inconscientemente, considera, sim, a questão estética, pois ver-se melhor ou pior posturalmente não constitui algo de caráter somente cognitivo, e, sim, afetivo-emocional.

Nesse momento do diálogo, notou-se a presença de duas perspectivas diferentes quanto às condições terapêuticas para a melhora: $\mathbf{P}$ queria ficar sem dor, mas negava-se a aceitar mudanças para que isso ocorresse, talvez para se proteger de temas dolorosos ou ocultar sentimentos que julga não serem pertinentes ao conhecimento de F. Já o "ficar sem dor", para F, exigiria mudanças na postura e na qualidade do sono. Vale lembrar, aqui, que não se trata de idealizar que as perspectivas de $\mathbf{F}$ e $\mathbf{P}$ possam ser idênticas, e sim, que haja negociação entre elas para se chegar a uma resolução.

Diante desse desequilíbrio, $\mathbf{F}$ dedicou-se a explicar mais sua perspectiva, o que possibilitou a continuidade da comunicação, sugerindo-nos que houve o reconhecimento, por parte de $\mathbf{F}$ e $\mathbf{P}$, da necessidade de se movimentarem juntas na busca de um objetivo comum. P demonstrou compreender o ponto de vista de $\mathbf{F}$, mas deixou claro que não acreditava em uma mudança postural, pois não tinha motivação para tal. Isso não pode ser analisado em termos de resistência à mudança ou de medo da transformação como acontecimentos isolados; deve ser entendido no contexto emocional de $\mathbf{P}$, pois, em outro momento, ela deixou claro que, por não ter sua família presente, sua vida havia perdido o significado, não sendo importantes as mudanças. F, valendo-se da percepção desse conteúdo emocional, buscou mudar a concepção de $\mathbf{P}$, argumentando que o fato de ela ter procurado auxílio para sair de uma condição física de dor para uma sem dor já denotava motivação pela mudança. Esse momento mostra uma tentativa de negociação de $\mathbf{F}$ em busca da (re)construção de novas concepções quanto à auto-estima de $\mathbf{P}$, incluindo um incentivo emocional na direção do "cuidar de si mesma", o que contribui simultaneamente para sua saúde física e mental, benefício aparentemente pequeno quando comparado ao que um acompanhamento profissional especializado poderia promover; entretanto, oportuniza pequenas mudanças, úteis no momento, para a continuidade do tratamento, mas com possível valor cumulativo.

Vale destacar também que, quando $\mathbf{P}$ disse ter uma postura ruim e por isso merecer a atenção dos filhos, tal fato nos sugeriu que essa condição ruim era privilegiada e até mesmo mantida por ela no intuito de chamar a atenção dos filhos, pois, em muitos outros momentos, $\mathbf{F}$ chamou-lhe a atenção para possíveis causas da dor "que estavam nela", no nível "corporal-objetivo" e, no entanto, $\mathbf{P}$ se referia a causas "que estavam fora dela", no nível "mental-psicológico", subjetivo, portanto. No entanto, $\mathbf{F}$ atribuiu a postura ruim de $\mathbf{P}$ à vida moderna, não valorizando as questões emocionais, assumindo assim uma concepção desintegrada da unidade corpo-mente. A solução desse conflito, diferentemente dos citados anteriormente, não gerou em ambas as participantes ações de reflexão e exploração de significados: $\mathbf{F}$ talvez tenha se baseado no pensamento dicotômico de que essas percepções emocionais de $\mathbf{P}$ não pudessem interferir negativamente em seus 
procedimentos; já para $\mathbf{P}$, o importante era que seus filhos soubessem da sua condição de dor, encontrando na má postura uma "prova cabal" para isso. As intenções, possivelmente inconscientes, de cada uma delas não entravam em sintonia e, portanto, não geraram reflexão na busca de consenso ou de aprofundamento de discenso.

\section{Segunda sessão}

$\mathbf{P}$ relatou que as alterações posturais observadas na sessão anterior por $\mathbf{F}$ lhe fizeram mal emocionalmente, indicando uma noção integrada de corpo e mente; no entanto, usou o termo "coisa" para denominá-las, como algo que não the pertencesse, mas como algo que havia se abatido sobre ela, denotando fragilidade na sua forma integrada de pensar. $\mathbf{F}$ não valorizou esse relato, dicotomizando corpo e mente, muito talvez por sua formação profissional não abarcar amplas discussões sobre a unicidade corpo-mente.

Outro tema abordado foi a realização de exercícios, que, por sua vez, gerou momentos de desequilíbrio, como os vistos na sessão anterior. F, por já ter familiaridade com a resistência de $\mathbf{P}$ às suas proposições, tentou validá-las usando argumentos mais amplos no contexto saúde-doença, como, por exemplo, o significado de ser um profissional da saúde e o papel de uma instituição de saúde. Utilizou, também, uma linguagem mais próxima à de $\mathbf{P}$, direcionando suas ações na integração corpo-mente, como no convite para que ela sentisse o efeito do exercício em seu corpo, voltando sua atenção para si mesma, em vez de buscar as causas de seu "sentir" nos outros, no que os outros the fazem ou deveriam fazer-lhe. $\mathbf{P}$ respondeu positivamente a esse novo "falar" de $\mathbf{F}$, mostrando que o convencimento se dava através da sensação corporal, isto é, a linguagem do corpo era capaz de modificar seu comportamento.
Ao final dessa sessão, $\mathbf{P}$ se mostrou satisfeita com os resultados obtidos, o que atribuiu somente ao trabalho de $\mathbf{F}$, talvez sustentada por uma condição cultural em que aos profissionais da saúde é atribuída a responsabilidade absoluta pelo sucesso ou não do tratamento. $\mathbf{F}$, diferentemente de $\mathbf{P}$, ciente da necessidade da disponibilidade interativa de ambas as partes para o sucesso do tratamento, torna claro essa condição a $\mathbf{P}$ e recebe a compreensão desta.

\section{Terceira sessão}

$\mathbf{P}$ chamou $\mathbf{F}$ pelo nome, indicando maior empatia e confiança em relação a ela e até mesmo mais disposição para o tratamento. Seus relatos, nessa sessão, mantiveram estreita ligação entre sentir dor e a necessidade de ter os filhos ao lado, ao se autodenominar inválida. Essa denominação foi contestada por $\mathbf{F}$, possibilitando a $\mathbf{P}$ repensar sua concepção de invalidez e, ao mesmo tempo, permitiu a F formular um possível significado para esse conceito no mundo de $\mathbf{P}$.

\section{Quarta sessão}

No início da sessão, $\mathbf{F}$ mostrou maior envolvimento com as questões emocionais de $\mathbf{P}$, mas não manteve esse sentimento, $\mathrm{o}$ que fez com que $\mathbf{P}$ propusesse a realização dos exercícios para sua distração, deixando transparecer que o pensamento dicotômico corpo-mente não lhe agradava. $\mathbf{F}$ atendeu a solicitação, disponibilizando-se a contemplar uma perspectiva diferente da sua sem, no entanto, abrir mão da própria, quando colocou que sua função profissional não abarcava a distração. Esse momento foi desafiador para a discussão das diferentes motivações "do fazer fisioterapia" - para $\mathbf{P}$, realizar os exercícios tinha o efeito de distração, nos sugerindo uma descrença pelo efeito mecânico do exercício sobre o corpo; já para $\mathbf{F}$, relevante era o efeito do exercício no corpo de $\mathbf{P}$ - mostrandonos mais uma vez, que, mesmo a partir de 
perspectivas diferentes, como era de se esperar, o consenso em realizar os exercícios foi alcançando.

Quinta sessão

Nessa sessão, $\mathbf{P}$ afirmou "sentir-se melhor" com a realização do tratamento, sugerindonos maior percepção de si mesma. Afirmou também que esse "sentir-se melhor" havia sido notado por seu filho, indicando que os benefícios do tratamento tinham ido além do corpo e alcançado suas relações familiares, possibilitando a ela abandonar a idéia de precisar estar doente para receber atenção. Outro momento que contribuiu para a idéia de que $\mathbf{P}$ passou a estar disponível para propostas novas, diferentemente das sessões iniciais, foi quando $\mathbf{F}$ alertou $\mathbf{P}$ sobre a necessidade de realizar exercícios em casa, fato inaceitável anteriormente, e ela respondeu que tentaria cumprir.

Sexta sessão

O final dessa sessão destacou um momento de tensão bastante único: $\mathbf{P}$ afirmou que $\mathbf{F}$ "não fazia só fisioterapia, fazia também psicoterapia". Imediatamente, $\mathbf{F}$ a contestou, alegando que sua formação profissional não permitia práticas psicoterapêuticas. No entanto, $\mathbf{P}$ colocou que o fato de $\mathbf{F}$ escutá-la, sem avaliá-la ou criticá-la, já a ajudava muito, o que fez com que $\mathbf{F}$ passasse a agir como ouvinte na continuidade do diálogo, mostrando ter incorporado a relevância dessa atitude.

Sétima a nona sessões

Nessas sessões, os relatos de $\mathbf{P}$ e $\mathbf{F}$ foram bastante recorrentes aos analisados até aqui, não merecendo destaque na presente discussão.

\section{Décima sessão}

Essa sessão foi marcada por tentativas de negociação e validação de opiniões sobre a continuidade ou não do tratamento: $\mathbf{P}$ afirmou ser necessário continuar o tratamento para sua dor não voltar; F contestou, alegando que suas condições físicas permitiam o encerramento, mas, buscando contemplar a opinião de $\mathbf{P}$, e não impor a sua, propôs que as sessões passassem a ser quinzenais, e não mais semanais. No mesmo intuito, $\mathbf{P}$ aceitou a proposta, solucionando o conflito.

\section{Contribuições semiótico- construtivistas para a prática interativa fisioterapeuta- paciente}

No diálogo analisado, notamos que as decisões de $\mathbf{F}$ para agir foram tomadas ora com a participação, ora sem a participação de $\mathbf{P}$. Quando F, em colaboração com $\mathbf{P}$, identificou o que supôs serem as necessidades de $\mathbf{P}$, e passou a agir nessa direção, houve mudanças nas atitudes de $\mathbf{P}$, assim como melhora em sua condição fisioterapêutica. Já as atividades propostas por $\mathbf{F}$ que não se assentavam na exploração de informações e construção conjunta de suposições com P a respeito do tratamento (expectativas, avaliações, etc.) parecem não ter resultado em novas significações para ambas. Tais propostas parecem, em alguns momentos, ter inclusive criado dificuldades na relação pacientefisioterapeuta, retardando o progresso no tratamento fisioterápico.

Houve, portanto, diferenças qualitativas no processo de tratamento, dependendo do envolvimento conjunto de $\mathbf{F}$ e $\mathbf{P}$ na exploração de informações e na construção de suposições sobre as intenções, os motivos e os demais aspectos subjetivos que instruíam seus fazeres e dizeres nas sessões. Ressalta-se, então, a importância do atendimento fisioterapêutico ser individual, pois só assim fisioterapeuta e paciente podem, efetivamente, dedicar-se à prática da construção e da reflexão sobre significados que dizem respeito não só à meta do diálogo mas também à posição relativa e momentânea dos interlocutores naquele diálogo, conforme Simão (2004). 
Merece destaque também a presença recorrente, nas sessões, de ações verbais de $\mathbf{F}$ pautadas na dicotomia corpo-mente, onde, ao centrar-se nos aspectos técnicos da profissão, fez também pouca alusão às repercussões sobre as possíveis intervenções de $\mathbf{P}$, evidenciando, nesses momentos, pouca abertura à participação desta. É possível que esse tipo de atitude, comum às práticas profissionais na área de saúde, se ancore na ênfase dada durante a própria formação profissional aos aspectos mais objetivos e instrumentais, considerados importantes para a consistência científica e profissional, havendo pouca disponibilidade para discussão e reflexão das questões atinentes aos aspectos subjetivo-emocionais aí envolvidos. Adicionalmente, nas formações e práticas profissionais, podem estar também envolvidas relações de poder, em que o corpo se torna um objeto que o profissional conhece e o paciente, não (e por isso vem ao profissional). Essas questões estão, por sua vez, vinculadas ao sistema comum de crenças culturais, que também se faz presente na gênese da profissão do fisioterapeuta (Rocha, 2002).

Em consonância com os estudos de Neville et al. (1999) e Van Houdenhove (2002), identificamos, no caso analisado, certa falta de disponibilidade de $\mathbf{F}$ para as questões emocionais no trato do paciente, o que comprometia o desenvolvimento da própria relação e, em conseqüência, o alcance do sucesso terapêutico. Saber ouvir é uma postura de respeito com o outro, para que se estabeleça uma comunicação que permita construir relações compartilhadas, nas quais se evidencie a "realidade" trazida pelo cliente, para a compreensão de seu viver e adoecer (Mariotti, 2000).

Essas constatações inquietam e fazem-nos questionar o foco de intervenção e atenção do fisioterapeuta: o corpo e sua motricidade. A ação da fisioterapia está voltada para o outro; com o nosso corpo, atuamos sobre o corpo do outro. E, quando falamos em atuar sobre o corpo do outro, falamos em reconhecer que o corpo do outro é sua expressão de vida, pois esse corpo, enquanto corporeidade, existe na relação com os outros, construída e reconstruída no "ser e se fazer fisioterapeuta/ paciente" (Simão, 2002). Por outro lado, dada a multiplicidade de conceitos envolvidos nas diversas abordagens psicológicas sobre as relações eu-outro bem como a complexidade envolvida nas escolhas teórico-metodológicas, não é difícil imaginar porque tais perspectivas dificilmente estão incluídas na formação do fisioterapeuta. Parece-nos, entretanto, que se trata de uma inclusão que deve ser intensificada na formação profissional, o que implica também maior interdisciplinaridade.

Em síntese, a pesquisa aqui ilustrada com a análise de um caso embasa nossa consideração do processo fisioterapêutico como espaço interativo. Fisioterapeuta e paciente, juntos, estão mergulhados em diferentes dimensões interativas, e desempenham funções inerentes aos papéis que lhes são reservados no processo terapêutico, mas permanecem em contínuas (re)significações no contexto intersubjetivo, que envolve relacionamentos humanos destinados ao cuidado e à cura e atuam de modo único ao compor as dimensões do corpo e da mente. Acreditamos que as considerações aqui destacadas são representativas da realidade profissional que conhecemos. Se as trazemos, é para argumentar que esse é um contexto que nos preocupa, e acreditamos ser necessário abordá-lo na formação dos futuros fisioterapeutas. Trata-se, a nosso ver, de manter as especificidades da formação em fisioterapia sem omitir uma perspectiva humanizadora do processo saúde-doença, ou seja, de exercer uma atuação reflexiva como profissionais das ciências médicas na fronteira com as ciências humanas. 


\section{Clóris Regina Elias de Moraes Canto*}

Mestre em Psicologia experimental pelo Instituto de Psicologia da Universidade de São Paulo; Fisioterapeuta do Hospital Israelita Albert Einstein.

\section{Lívia Mathias Simão}

Professora Livre-Docente do Departamento de Psicologia Experimental do Instituto de Psicologia da Universidade de São Paulo; Bolsista de produtividade em Pesquisa do CNPq

\section{*Endereço para envio de correspondência:}

Rua César Vallejo, 300, Ap.211 - Real Parque, São Paulo - SP - Brasil, CEP: 05685-000

E-mail: cloriscanto@hotmail.com

Recebido 26/02/2008 Reformulado 16/01/2009 Aprovado 20/01/2009

\section{Referências}

Abbey, E., \& Valsiner, J. (2003). Emergence of meanings through ambivalence. Trabalho apresentado na European Conference on Developmental Psychology, Milão.

Abraham, A. (1963). Le dessin d'une personne (Le test Marchover). Neuchâtel: Delachaux et Niestlé.

Boesch, E. E. (1977). The medical interaction. A study in Thailand. The German Journal of Psychology, 1(1), 13-28.

Boesch, E. E. (1991). Symbolic action theory and cultural psychology. Berlin: Springer - Verlag.

Canto, C. R. E. M. (2006). O relacionamento dinâmico entre fisioterapeuta e paciente e a integração corpo-mente: um estudo de caso. Dissertação de Mestrado, Instituto de Psicologia, Universidade de São Paulo, São Paulo.

Catan, L. (1989). The dynamic display of process: Historical development and contemporary uses of microgenetic method. Human Development, 29, 252-263.

Denys-Struyf, G. (1995). Cadeias musculares e articulares: o método G.D.S./Goodelieve Denys-Struyf. São Paulo: Summus.

Gonçalves, M. A. S. (1994). Sentir, pensar, agir. Corporeidade e educação. Campinas, SP: Papirus.

La Taille, Y. (2002). Vergonha, a ferida moral. Petrópolis, RJ: Vozes.

Mariotti, H. (2000). As paixões do ego: complexidade, política e solidariedade. São Paulo: Palas Athenas.

Marková, I. (1997). On two concepts of interaction. In M. Grossen \& B. Py (Eds.), Pratiques sociales et mediations symboliques (pp. 23-44). Bern \& Berlin: Peter Lang.
Neville, C., Fortin, P. R., Fitzcharles, M. A., Baron, M., Abrahamowitz, M., Du BeRGER, R., \& Esdaile, J. M. (1999). The needs of patients with arthrits: The patient's perspective. Arthritis Care and Research, 12(2), 85-95.

Rocha, V. M. (2002). Do corpo à corporeidade: repensando os saberes na formação do profissional fisioterapeuta. Tese de Doutorado em Ciências Sociais e Aplicadas, Universidade Federal do Rio Grande do Norte, Natal.

Schilder, P. (1980). Imagem do corpo. As imagens constitutivas da psique. São Paulo: Martins Fonte.

Simão, L. M. (2000). Desequilíbrio e co-regulação em situação de ensino-aprendizagem: análise segundo o conceito de ação comunicativa (Habermas). Psicologia: Reflexão e Crítica, 13(1), 33-38.

Simão, L. M. (2002). O significado da interação verbal para os processos de construção de conhecimento: proposta a partir da ótica boeschiana. In S. A. S. Leite (Org.), Cultura, cognição e afetividade: a sociedade em movimento (pp. 85-102). São Paulo: Casa do Psicólogo.

Simão, L. M. (2004). Alteridade no diálogo e construção de conhecimento. In L. M. Simão \& M. A. Martinez (Orgs.), O outro no desenvolvimento humano - diálogos para a pesquisa e a prática profissional em psicologia (pp. 29-39). São Paulo: Pioneira Thomson Learning.

Van Houdenhove, B. (2002). Listening to CFS. Why we should pay more attention to the story of the patient. The Journal of Psychosomatic Research, 52, 495-499. 